\title{
História Pública as memórias da hanseníase no Hospital Colônia Santa Teresa (Santa Catarina/Brasil)
}

\section{Public History - memories of leprosy at Hospital Colônia Santa Teresa (Santa Catarina / Brazil)}

\author{
Recebido em: 04/01/2019 \\ Aceito em: 10/01/2019 \\ Viviane Borges ${ }^{1}$ \\ Daniela Pistorello
}

\begin{abstract}
Resumo:
O artigo trata de um trabalho de pesquisa-ação realizado no Hospital Colônia Santa Teresa, antigo leprosário de Santa Catarina (Brasil). Este trabalho propôs inicialmente uma atividade envolvendo pacientes e funcionários da Instituição e alunos da Universidade do Estado de Santa Catarina, e teve como resultado uma exposição idealizada e protagonizada pelos sujeitos sociais que vivem ou viveram no local ou que, de alguma forma, tiveram algum envolvimento com a hanseníase naquele espaço. De forma geral, o processo coletivo de criação da exposição seu deu por meio de Rodas de Conversa, nas quais se buscou apresentar a hanseníase no estado através da exposição Lugar de morar, lugar de cuidar. Apresentaremos os bastidores do processo de criação da referida exposição como um processo de patrimonialização, fundamentado a partir de uma experiência colaborativa.
\end{abstract}

Palavras-chave: História Pública, oralidade, hanseníase, patrimônio cultural, patrimônios difíceis.

\section{Abstract: \\ This article is about an action-research study carried out at the Colônia Santa Teresa Hospital, a former leprosarium in Santa Catarina (Brazil). Initially, this action proposed an activity involving patients and employees of the Institution and students of the Universidade do Estado de Santa Catarina, and}

\footnotetext{
1 Doutora em História pela Universidade Federal do Rio Grande do Sul (UFRGS). Professora do Departamento de História e Programa de Pós-Graduação em História da Universidade do Estado de Santa Catarina (UDESC).

2 Doutora em História pela Universidade Estadual de Campinas (UNICAMP), Pós-doutora pela Universidade do Estado de Santa Catarina (UDESC).
} 


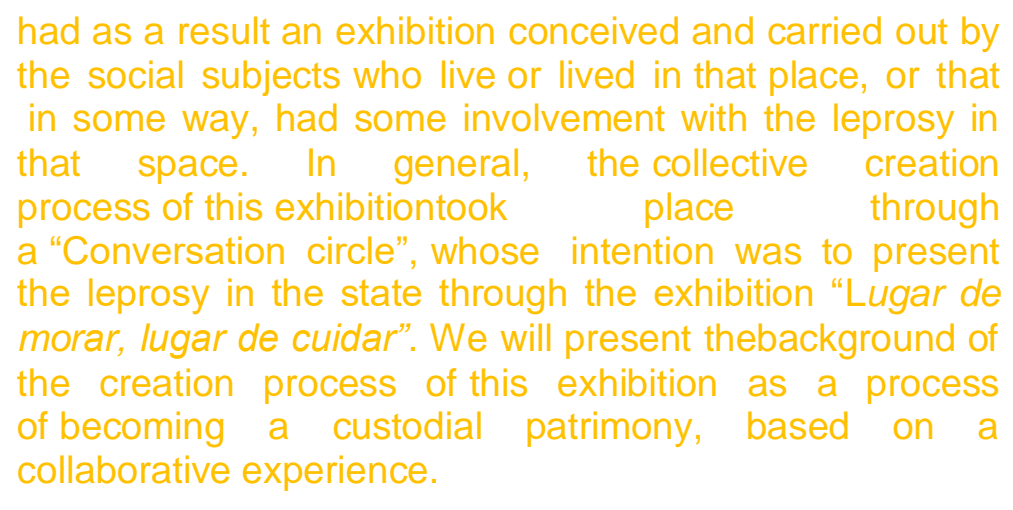

Keywords: Public History, orality, leprosy, cultural patrimony, difficult patrimony.

\section{Introdução}

A história da hanseníase no Brasil vem sendo amplamente estudada, perpassando a história das instituições e dos sujeitos que nelas foram confinados, através de pesquisas que se utilizam principalmente da história oral e da memória como elementos primordiais para contar uma história marcada por memórias difíceis. Não é objetivo aqui adentrar neste terreno amplo de possibilidades, pois isso excederia a proposta do presente artigo, mas apenas recorrer à historiografia sobre o tema a fim de trazer alguns elementos que possibilitem ao leitor a compreensão do contexto que permitiu a criação do Hospital Colônia Santa Teresa.

A história da instituição é atravessada por demandas sociais do presente e por potencialidades marcadas por memórias difíceis, evidenciando a contemporaneidade do não contemporâneo (DOSSE, 2012), mostrando as filigranas de um discurso que ainda é carregado de estigmas.

O Hospital Colônia Santa Teresa, conhecido atualmente como Hospital Santa Teresa de Dermatologia Sanitária, foi construído no período de 1938 a 1940 em Santa Catarina. Seu principal objetivo foi o de se tornar uma instituição asilar destinada a isolar compulsoriamente as pessoas acometidas pela hanseníase, doença até então conhecida como lepra ${ }^{3}$.

Com uma área de aproximadamente 9.500 km², o Hospital Colônia Santa

\footnotetext{
3 No Brasil, a comprovação da força negativa agregada ao termo lepra e seus derivados, esteve na necessidade de se criar uma legislação que proibisse seu uso em documentos oficiais (Lei 9.010, 1995). De lepra para hanseníase, a mudança do nome visava diminuir o peso do estigma inerentes aos termos lepra e leproso (MACIEL, 2004; p. 112). Por esta razão, no restante do texto usaremos o terno Hanseníase.
} 
Teresa está localizado a aproximadamente $30 \mathrm{~km}$ de Florianópolis, capital do estado de Santa Catarina. Seguindo a proposta da época para este tipo de instituição, além dos pavilhões destinados à internação e tratamento da doença, sua estrutura era composta de enfermarias, lavanderias, prefeitura, delegacia, cadeia, igreja, teatro, escola, cinema, campo de futebol e cemitério, além de possuir moeda própria, pois acreditava-se que circulação de dinheiro pudesse ser uma das formas de contágio.

Da mesma forma, a vida dos que estavam ligados ao hospital colônia era regulada por normas e regras, mas para os pacientes o sistema era mais rígido. Seu cotidiano era pautado por meio de uma série de normas que estabeleciam comportamentos e horários para trabalho, lazer e tratamento médico. Essas relações envolviam decisões divididas entre o governo do estado, representado pela figura do diretor do Hospital, e a Ordem Franciscana, que se incumbia das atividades administrativas e cuidados necessários para a assistência dos internos, como, por exemplo, a troca de curativos.

As visitas aos familiares se davam em lugares denominados parlatórios, que se tratava de uma área exclusiva e isolada das demais e destinada a recebê-los, para que o contato físico não fosse possível. A separação entre pais e filhos era instituída por lei e visava igualmente barrar as possibilidades de contágio. Os filhos dos internados eram enviados aos preventórios, onde ficavam até a maioridade ou enviados para adoção, que muitas vezes não seguia nenhuma formalidade legal (SILVA, 2009); no caso de Santa Catarina eram enviados ao Educandário Santa Catarina, $\theta$ preventório construído para este fim (MATTOS, 2002). Como alguns pacientes ficavam internados por longos períodos, muitas deles viveram em tais instituições durante décadas; estes buscaram reconstituir vínculos dentro da instituição, sendo comuns os casamentos com filhos ${ }^{4}$. Lidavam com uma forma de viver que era marcada pela ambiguidade, pois alguns relatos e documentos institucionais mostram que eram comuns as tentativas de fuga da instituição, mas, por outro lado, é evidente que os internos - juntamente com os funcionários da instituição e representantes da ordem franciscana que lá atuaram, - criaram uma sociabilidade que tornava suportável e menos pesada a vida nos hospitais colônia.

Nada do que foi descrito até aqui foi uma exclusividade do Hospital Colônia Santa Teresa. A instituição foi uma dentre os 33 espaços construídos para abrigar os

\footnotetext{
${ }^{4}$ Decreto $n^{\circ}$. 16.300, de 31/12/1923 e Decreto №. 610, de 13 de janeiro de 1949.
} 
acometidos pela hanseníase no Brasil. Único existente no estado, chegou a abrigar cerca de 800 pessoas em suas primeiras décadas de funcionamento, recebendo pacientes de várias localidades. Dentre as centenas que passaram por lá, 15 são os remanescentes que residem e vivem naquele espaço que atualmente se constitui em uma referência em dermatologia sanitária e cirurgias bariátricas do estado de Santa Catarina.

Homens e mulheres que deixaram fora do Hospital parte de suas vidas, hoje convivem com uma imponente estrutura física, que funcionou como uma verdadeira cidade, com funções exclusivamente ligadas ao tratamento da hanseníase, mas que hoje ganha novos usos. Os pavilhões, a enfermaria, o teatro, o campo de futebol, a sala de cinema e outros tantos lugares que abrigavam as pessoas que por ali passaram, não existem mais, mas deixam espaços vazios, hoje em parte ressignificados e reutilizados. Da mesma forma, o mobiliário, o relógio de ponto, os livros de registro, as fotografias e os tantos objetos que fizeram parte do cotidiano dessas pessoas são resquícios do passado, mas que se constituem em vetores de uma memória que ressignifica esse tempo. Embora ainda exista um portão que separa o espaço do Hospital Colônia da área externa, talvez sejam os muros invisíveis que ainda apartam os internos da sociedade, ao mesmo tempo que os protegem. Esses locais de internamento, ainda que revestidos de um caráter benevolente de tratamento, remetem a uma faceta cruel do passado marcada pelo isolamento compulsório e a estigmatização das pessoas que por lá passarem e/ou viveram.

\section{Um lugar de muitas memórias}

Os primeiros contatos com o hospital se deram por meio do projeto de extensão Arquivos Marginais, ${ }^{5}$ do Laboratório de Patrimônio Cultural (LabPac), que atua na organização de acervos de instituições de isolamento como o Hospital Colônia Sant'Ana e a Penitenciária do Estado. A ações desenvolvidas no âmbito deste Projeto acabaram tendo visibilidade em outras instituições que possuem demandas muito semelhantes, foi o que aconteceu em 2016, com o Hospital Santa Teresa, que no caso, solicitava que a Universidade do Estado de Santa Catarina auxiliasse, através

\footnotetext{
${ }^{5}$ O Projeto Arquivos Marginais existe desde 2011 e mantido pelo Laboratório de Patrimônio Cultural da UDESC (LabPac/UDESC). É uma é uma pesquisa-ação que trata da salvaguarda de acervos ligados a instituições de aprisionamento, como hospitais psiquiátricos, prisões e leprosários.
} 
do Projeto Arquivos Marginais, a criar um espaço que pudesse agregar informações a respeito da hanseníase em Santa Catarina.

A demanda inicial do Hospital era pela criação de um Memorial dentro da instituição, contudo, uma série de discussões a respeito da possibilidade do fechamento do hospital e as constantes trocas de direção nos últimos meses de 2017 , modificaram o desfecho do trabalho. Como resultado possível propomos uma exposição dentro da Universidade durante a semana anual de eventos proposta pelo Centro de Ciências Humanas e da Educação (FAED), contando com intervenções dos alunos do curso de graduação em História da UDESC.

Para atender ao objetivo deste artigo, o texto se divide em dois momentos: o primeiro situa a questão da patrimonizalição de lugares difíceis, e o segundo discute os sentidos atribuídos à História Pública e a construção da exposição como uma prática da mesma. Tal metodologia pressupõe a proposição e execução de algo realizado com os sujeitos e grupos envolvidos, procurando entender a maneira como esses contam as histórias que consideram importantes (BORGES, 2016).

\section{“Outros" patrimônios}

No Brasil a temática dos "outros" patrimônios tem aparecido como agenda de pesquisa, ligando o tema aos patrimônios difíceis, às demandas sociais e a história pública (BAUER e BORGES 2018), (BORGES, 2018a, 2018b). O já tão reiterado alargamento da noção de patrimônio cultural, a elasticidade de suas tipologias e representações, tem sido acompanhada pela possibilidade de participação cidadã nos processos de patrimonialização. Uma abertura é invariavelmente assinalada pela instigação a participação dos sujeitos diretamente envolvidos, trazendo novos e extraordinários desafios ao campo do patrimônio cultural em seu diálogo com a História Pública (BAUER e BORGES, 2018).

Sob a perspectiva da Constituição de 1988 e seu tão citado artigo 216, passamos a entender como patrimônio os bens de natureza material e imaterial referentes à "identidade, à ação, à memória dos diferentes grupos formadores da sociedade brasileira" (BRASIL, 1988). Contudo, ainda se trata um caminho tortuoso e marcado pela ausência de incentivo a ações práticas que atendam de fato a pluralidade de identidades e manifestações (BAUER e BORGES, 2018)

Essa abertura do conceito de patrimônio cultural a partir principalmente das 
ultimas décadas do século XX nos permite pensar não estamos só tratando de novos patrimônios, mas também novas sociedades: "mais descentralizadas, mais escolarizadas, mais permeáveis a culturas científicas, mais dotadas de especialistas e profissionais especializados, sociedades com maiores reivindicações de participação e de afirmação identitária, mais heterogéneas" (PEIXOTO, 2009, p. 4).

O patrimônio deve atender ao presente, às suas demandas e a seus usos. Se atualmente ouvimos demandas pela volta da ditadura e a relativização da tortura nos discursos políticos é porque não apreendemos nada com a história, com os lugares de memória de sofrimento cuidadosamente preservados. ${ }^{6} \mathrm{O}$ sentido pedagógico de preservar para que isso ou aquilo não mais se repita nunca pareceu tão esvaziado de sentidos. Para além do sentido pedagógico, os patrimônios difíceis devem ser preservados porque

"Incomodam, ameaçam penetrar no presente de forma perturbadora explicitando problemas sociais marcados por embates éticos. Uma herança desajeitada que provoca, entre outras coisas, questões sobre memória e passado, sobre as práticas de seleção e preservação" (BORGES, 2018).

No que tange aos antigos leprosários observamos a ausência de políticas públicas federais propostas especificamente para essas construções. A proteção destes espaços, quando ocorre, parte do âmbito estadual. O caso mais notório é o de São Paulo, onde o Conselho de Defesa do Patrimônio Histórico Arqueológico, Artístico e Turístico (CONDEPHAAT), responsável pela salvaguarda do patrimônio no estado, tombou como exemplares dos asilos-colônia, cinco asilos-colônia considerados nacionalmente pioneiros nesta categoria: Santo Ângelo (Mogi das Cruzes), Padre Bento (Guarulhos), Pirapitingui (Itu), Cocais (Casa Branca) e Aimorés (Bauru).

O objetivo geral desta ação em São Paulo foi preservar os antigos asilos-colônia como registros de uma prática que definiu um território do interior do estado marcado pela presença da doença, bem como as formas de percepção e de profilaxia da mesma. "Constituem, portanto, a materialização dos estigmas socioculturais revestidos

\footnotetext{
${ }^{6}$ Um exemplo importante diz respeito ao tombamento, em 2014, das antigas instalações do Doi-Codi (Destacamento de Operações de Informações do Centro de Operações de Defesa Interna), local onde funcionam atualmente o prédio e os anexos do $36^{\circ}$ Distrito Policial, a delegacia da região de Vila Mariana. Durante a Ditadura civil-militar no Brasil, aquele espaço era um dos lugares de repressão, onde vários presos políticos foram interrogados, torturados e assassinados. O pedido de tombamento feito pelo presidente do Conselho do Defesa dos Direitos da Pessoa Humana (CONDEPE) foi aceito sob a justificativa de que se trata de um patrimonio material que evoca as memórias de um momento longo e sombrio da história brasileira recente.
} 
de bases científicas, imputados a milhares de portadores da doença por décadas" (CAPORRINO e UNGARETTI, 2016, p. 159). Os processos de tombamento nos permitem perceber vários aspectos importantes das colônias: contém dados expressivos referentes à arquitetura das edificações que marcaram uma estética da organização espacial das colônias e sua relação com a hanseníase e a saúde pública; possibilitam conhecer as formas como os internos recriaram suas vidas quando foram segregados e viveram em isolamento, além de poder oportunizar aos pacientes e seus descendentes o reconhecimento de seus direitos de reparação.

Sem dúvida, esse movimento de patrimonialização instaura o debate sobre a potencialidade deste patrimônio e das memórias a ele ligadas, uma vez que, minimamente, estamos diante de um patrimônio diferente daquele que o consenso construiu e sacralizou historicamente (CHOAY, 2006) pois são espaços ligados a memórias difíceis (RICOEUR, 2007) e que muitas vezes por rememorarem a dor dos processos vividos, são também assim considerados. No processo de patrimonialização desses espaços,

\begin{abstract}
"Ganham destaque as mencionadas memórias traumáticas que, de certo modo, também remetem a topos da história mestra na vida, porém, dessa vez, com foco no que não se deve repetir jamais, e a uma imagem de futuro, percebido não como certeza de algo melhor, mas como ameaça de repetição da dor, a qual só poderia ser evitada a custo de rememoração periódica das violências passadas." (SCHMIDT, 2014, p. 33)
\end{abstract}

\title{
História pública e as demandas do presente
}

O processo de constituição de lugares de memória dentro de espaços ligados a situações traumáticas tem duas constantes distintas. De um lado, podem recair em silenciamento resultante da transferência de legitimidade conferida a uma instituição "oficial" de memória, de outro, pode criar a possibilidade de debates de memória sobre práticas e episódios controversos (SEVCENKO, 2016).

Sob a perspectiva da história pública foi nossa intenção criar um espaço de debate sobre as memórias relacionadas com a história da hanseníase. O processo de internacionalização da história pública vem possibilitando sua apreensão em diferentes contextos, tornando quase impossível uma única definição comum às diferentes nacionalidades (NOIRET, 2017, p. 13). A história pública no Brasil está ligada às variadas práticas comunitárias que dialogam com a história social, história cultural e políticas de memória (NOIRET, 2017, p. 10). Assim, partimos de duas 
chaves de história pública que são a história para o público e história com o público. Entendemos história pública como um campo de trabalho que potencializa e amplia as possibilidades de inserção do historiador e também como um movimento de difusão e reflexão histórica a esse respeito (CORRÊA, 2014, p.1). Considerando ambas perspectivas, o público tem grande importância durante todo o processo, deixa de ser um simples consumidor e/ou expectador a receber a informação pronta, tornando-se parte ativa de toda a tessitura do trabalho: mais que isso, torna-se seu coautor.

Esse modelo de história colaborativa remete a noção de "autoridade compartilhada", proposta por Michael Frisch (1990). Invertendo a perspectiva usual de difusão cultural como o movimento de "levar" o conhecimento ao público, o autor propõe uma pesquisa-ação voltada a "compartilhar e reconhecer autoridades", entendendo que tanto as entrevistas de história oral quanto as exposições de museu, são resultados de uma coautoria.

Em palestra recente, durante a 4th Annual Conference da International Federation for Public History, Frisch (2017) retomou o conceito propondo um sutil deslocamento, de "autoridade compartilhada" para "autoridade de compartilhamento", e convidando a um novo caminho.

\begin{abstract}
"A "Autoridade de compartilhamento" implica que isso é algo que nós fazemos ou devemos fazer - que "nós" temos autoridade e que precisamos ou devemos compartilhá-la com outras pessoas. A mensagem parece ser que a autoridade de compartilhamento é uma coisa boa, então vamos fazer mais disso. Em contraste, "A Shared Authority", sugere algo que "é" - isto na natureza da história oral e pública, "nós" não somos a única autoridade, os únicos intérpretes, os únicos autores-historiadores" (livre tradução das autoras).
\end{abstract}

Frisch mostra que ao invés disso devemos pensar que o processo interpretativo e o processo de criação de significado já são, por definição, compartilhados. Segundo ele, precisamos reconhecer essa autoridade nos documentos que geramos e nos processos dialógicos da história pública. Dessa forma, criar uma exposição, com os sujeitos envolvidos, significa estar atento ao encontro de diferentes quadros e ideias interpretativas, um diálogo entre "expertise" e experiência, buscando encontrar maneiras, nem sempre fáceis, de agir dentro desse reconhecimento (FRISCH, 2017, p. 11). No que tange a proposta aqui apresentada, uma das formas encontradas foi através das Rodas de Conversa, uma metodologia participativa que articula questões advindas da psicologia social, da psicanálise e da educação, tendo como foco a criação de um espaço de reflexão, no qual os envolvidos 
possam refletir a respeito de seu cotidiano e suas relações com o mundo (AFONSO, ABADE, 2008). As Rodas de Conversa foram momentos de escuta e fala.

\begin{abstract}
"No contexto da Roda de Conversa, o diálogo é um momento singular de partilha, uma vez que pressupõe um exercício de escuta e fala. As colocações de cada participante são construídas a partir da interação com o outro, sejam para complementar, discordar, sejam para concordar com a fala imediatamente anterior. Conversar, nesta acepção, remete à compreensão de mais profundidade, de mais reflexão, assim como de ponderação, no sentido de melhor percepção, de franco compartilhamento" (MOURA, LIMA, 2014).
\end{abstract}

Proposta semelhante vem sendo realizada pelo curso de Museologia, da Universidade Federal do Rio Grande do Sul, em parceria com o Museu Comunitário da Lomba do Pinheiro, localizado em Porto Alegre/RS, no projeto intitulado "Programa Lomba do Pinheiro: memória, informação e cidadania". As Rodas de Memória ou Rodas de Conversa, possibilitam a interação com os sujeitos envolvidos, fornecendo as condições necessárias para que estes possam se reconhecer e serem reconhecidos como parte da história que se deseja contar. A metodologia proposta intencionou "fomentar o respeito ao passado, real ou imaginário, o sentimento de pertencimento a um dado grupo, a consciência coletiva e a preocupação com a individualidade, com a memória e com a identidade" (ZEN, 2014, p. 360).

As rodas são momentos de escuta e fala. No caso do projeto em questão, que buscava criar um espaço - que denominamos de Memorial - no qual o objetivo era reunir elementos sobre a hanseníase em Santa Catarina, as rodas de conversa foram fundamentais. Através delas que foi possível ouvir dos pacientes suas diversas narrativas acerca das suas experiências com a doença, seu cotidiano no hospital. As Rodas de conversa foram organizadas partindo de algumas inquietações: Como os hoje ex-hansenianos percebem o espaço do hospital? O que lhes é significativo? Quais narrativas constroem acerca da doença e de sua internação a partir de suas experiências? Como dar conta das demandas institucionais, do Hospital e da UDESC e dos anseios daqueles que desejam ter uma representação de suas memórias?

As Rodas mostram a potência da oralidade, fazem "transparecer e respirar, no emaranhado de vozes que tecem (ou deveriam tecer) os processos de patrimonialização em seus múltiplos sentidos, a oralidade em sua riqueza e multiplicidade, na tentativa de através dela problematizar outros patrimônios, outras memórias" (BORGES e BAUER, 2018). São exercícios de fala e escuta, que tomam a "história oral não como método de pesquisa, mas como um instrumento para a criação 
de comunidades de escuta e compartilhamento de histórias" (SANTHIAGO, 2018, p. 146).

O objetivo das Rodas de Conversa foi ouvir dos pacientes suas diversas narrativas acerca de suas experiências no Hospital Colônia e, a partir delas, esboçar os temas que seriam contemplados na exposição. Ricoeur (2010) afirma que é por meio das narrativas que se torna possível a experiência humana no tempo; são as narrativas que descrevem ações e experiências dos sujeitos envolvidos, personagens representados em situações que mudam ou reagem a ela (RICOEUR, 2010, p. 112). A experiência do confinamento compulsório da hanseníase vem sendo constantemente revisitada, permitindo que novos sentidos sejam atribuídos a esse passado por diferentes segmentos sociais e pelos protagonistas dessa história (GROOT, 2016). Captar esses sentidos e entender os aspectos considerados relevantes dentro da experiência de internamento foi nosso objetivo inicial.

A primeira Roda foi realizada em março de 2016, contando com a presença de pacientes, egressos e seus familiares, funcionários do Hospital, comunidade local e alunos da disciplina de 'Patrimônio Cultural', do curso de graduação em História da Universidade do Estado de Santa Catarina. Na ocasião foram relatadas trajetórias de vida dentro do Hospital Colônia, identificados personagens e histórias consideradas importantes. Também foi o momento de escutar as expectativas destes sujeitos em relação ao nosso trabalho, buscando compreender como os envolvidos desenvolvem seus sentidos de passado. A primeira escuta dos protagonistas dessa história proporcionou os temas de cotidiano e sociabilidade.

A segunda e a terceira Rodas, ocorridas em abril e maio de 2017, foram novamente repletas de narrativas pessoais, mostrando o cotidiano em termos de sociabilidade, com conversas sobre casamentos, futebol, encenações teatrais, trabalho etc. As Rodas de Conversa ajudaram a diminuir a distância entre a Universidade e a instituição, e entre os pesquisadores e os pacientes/moradores, possibilitando o início de um conjunto de entrevistas que estão sendo realizadas e que futuramente darão origem a um arquivo de fontes orais/depoimentos. O contato com os protagonistas dessa história indicou os fios condutores da exposição a ser realizada para inauguração do Memorial.

Aliás, é importante ressaltar que até então, o Projeto considerava criar/organizar o Memorial numa edificação (uma casa de alvenaria) localizada dentro da área do Hospital Santa Teresa, mas fora dos muros do espaço onde se localizavam 
os pavilhões de tratamento dos pacientes. A escolha apor essa edificação se justificava porque historicamente era vista como o "Museu" do Hospital, pois apesar de estar em péssimas condições, abrigava alguns objetos relativos ao cotidiano do Hospital, fotografias e documentos dispersos. Em paralelo às Rodas, entrevistas, pesquisas e demais ações que envolveram o Projeto, além de organizarmos os espaços que receberiam a exposição, arrolamos todos os objetos que se encontravam deste local, digitalizamos o material e entregamos para a direção do Hospital.

No entanto, no meio deste processo, houve a troca da diretoria do hospital, que é gerido pelo Governo do Estado de Santa Catarina - e rumores de que o mesmo seria fechado. Isso gerou uma celeuma na comunidade que, de forma organizada, se reuniu para protestar contra o possível fechamento da instituição. ${ }^{7}$ Esse fato repercutiu por alguns meses gerando diversos impactos no hospital e na comunidade. Um deles, infelizmente negativo, foi a impossibilidade de utilizar a edificação para abrigar o Memorial. Diante disso, ao invés de trabalharmos como produto final a organização de um memorial que envolvia objetos tridimensionais, fotografias e demais documentos, materializamos nosso trabalho na forma de uma exposição utilizando para isso, banners.

De qualquer forma, independentemente do formato que assumiria nosso produto final, as narrativas provenientes das falas dos sujeitos envolvidos giravam em torno de temas como Cotidiano e Sociabilidade.

A partir dessas falas e das pesquisas realizadas, construímos discursos sobre o tema que compôs a exposição "Lugar de viver, lugar de cuidar: narrativas sobre a hanseníase em Santa Catarina". Nossa intenção era justamente contar uma história da hanseníase no estado, como demandava a instituição, mas a partir de uma perspectiva que envolvesse os interessados, os protagonistas daquela temática.

Conforme Serres e Borges (2015, p. 214):

\begin{abstract}
"A memória da lepra, é uma memória que não se reivindica - ou não se reivindicava - ela é estigmatizante, gerou e gera muito sofrimento para os afetados, problematizar essas memórias por meio de lugares de preservação e estudo pode ajudar esses grupos a conviver com o passado traumático e ajudar a desestigmatização da doença."
\end{abstract}

\footnotetext{
7 A mídia regional publicizou através de matérias de jornais e telejornais esses movimentos ocorridos entre os dias 27 de julho a 15 de agosto, como, por exemplo fez o jornal Notícias do Dia. Disponível: https://ndonline.com.br/florianopolis/noticias/manifestacao-pede-a-continuidade-do-hospital-santa-teresaem-sao-pedro-de-alcantara. Acesso em 05 out. 2018.
} 
Nesse sentido, criar uma Exposição para contemplar as diversas narrativas sobre a lepra em Santa Catarina, a partir daqueles que a vivenciaram, não tem o objetivo de rememorar um passado traumático e/ou alimentar estigmas acerca da doença e do seu tratamento. Também não intenciona insistir em visões maniqueístas que tratem, de um lado o paciente e, de outro, a instituição asilar, mas tem como horizonte oportunizar que se pense a doença e seu tratamento ao longo da história, possibilitando sua desmistificação e diminuição do preconceito em relação a ela e seus portadores. Nossa perspectiva é de que a Exposição possa ser um instrumento que permita auxiliar a recuperar a autoestima desses sujeitos e permita o empoderamento de suas ações como cidadãos, motivando a reivindicação por seus direitos e a diminuição dos obstáculos que separam os moradores do Hospital Colônia Santa Teresa do restante da sociedade.

Estabelecemos o esforço de pensar o tema a partir de uma noção de fazer a história com os sujeitos envolvidos, procurando perceber a maneira como eles estão contando as histórias que consideram importantes, entendendo que a prática histórica não se limita aos ambientes acadêmicos. Por ter abrigado centenas de pessoas durante o período de sua existência, por ter sido a "lepra" um termo repleto de sentidos depreciativos que faziam com que seus portadores e familiares sofressem com estigmas, preconceito e exclusão, justifica-se a importância da criação da exposição. Foi a partir desses referenciais que empreendemos o desafio de construir 0 Memorial e tão logo as Rodas de Conversa apontavam o desejo e a importância de criá-lo, começamos a pensar em possíveis locais para sua execução, bem como de que forma deveria se constituir.

Uma das demandas que surgia das Rodas de Conversa era em relação aos objetos antigos depositados em um dos prédios do Hospital. Eles fariam parte da proposta de criação de um Memorial. Os participantes nos alertavam para a quantidade e diversidade dos objetos e o grau de deterioração de algumas peças devido ao cupim. Em vista disso, uma das primeiras atividades desenvolvidas foi sua identificação e registro, bem como limpeza e acondicionamento. Nesta etapa, contamos com o trabalho voluntário de uma museóloga e uma aluna do curso de graduação em História, que trabalharam por cerca de três meses nestas atividades. Ao mesmo tempo em que este trabalho era desenvolvido, organizamos reuniões semanais com a direção do hospital que, sempre solícita, se disponibilizava em auxiliar no processo. 
Após seis meses de trabalho que envolveu a criação das Rodas de Conversa, pesquisa, entrevistas, limpeza, seleção e arrolamento dos objetos, seleção de fotografias e muitas reuniões, chegamos a um consenso a respeito da forma como conceberíamos a Exposição.

Reunimos estes condicionantes e em conjunto com os atores sociais do processo, pensamos numa narrativa que contemplasse os seguintes temas: moradia, tratamento, cotidiano e sociabilidade. Assim, a exposição foi nominada de: 'Lugar de cuidar, lugar de morar - a hanseníase no estado de Santa Catarina'.

Dessa forma, a exposição foi pensada e idealizada. O primeiro banner teve como tema principal a apresentação do espaço institucional: 'Que lugar é este?' Para responder esta questão, utilizamos vários elementos, como duas imagens do Hospital (uma planta baixa e uma vista aérea); fotografias das casas e dos pavilhões e imagens de objetos ligados ao cotidiano administrativo do Hospital e um pequeno texto apresentando dados pontuais sobre a história institucional do Hospital Colônia e seu principal objetivo.

O segundo e o terceiro banners foram nomeados de "Cotidiano, sociabilidades e trabalho" e para elas selecionamos imagens e textos que dialogassem com as práticas de lazer, de sociabilidade e as atividades desenvolvidas pelos internos no espaço do Hospital. Optamos por reproduzir fotografias dos atuais moradores, bem como fragmentos de suas falas que, colhidos nas entrevistas, deram a tônica do tema.

A quarta temática foi destinada a problematizar os diferentes tratamentos médicos realizados no Hospital e selecionamos objetos de enfermaria e utensílios relacionados ao tema, juntamente com informações técnicas pertinentes. Por fim, destinamos o espaço do corredor para destacar o papel Congregação Franciscana no Hospital, selecionando para isso objetos sacros bem como fotografias que ilustrassem um pouco das atividades desenvolvidas e coordenadas pelos religiosos.

A exposição ocorreu dentro da Universidade durante a semana anual de eventos proposta pelo Centro de Ciências Humanas e da Educação (FAED), contando com intervenções dos alunos do curso de graduação em História da UDESC, como dados atuais sobre a doença no Estado, um detalhamento da história dos filhos dos hansenianos e os preventórios, fotografias atuais da instituição e depoimentos de funcionários de antigos funcionários.

Problematizar o sofrimento vivido por meio de ações motivadas por políticas de memória provoca a reflexão, possibilitando a conexão entre passado e presente. No 
Brasil a hanseníase é um passado que não quer passar. Segundo dados da Organização Mundial da Saúde, de janeiro de 2016, o Brasil é o país com maior concentração de casos e maior índice de prevalência da doença no mundo, sendo o único país em que a doença não está em processo de eliminação, seguido pelo Timor e pelo Nepal (BORGES e MENEGUELLO, 2018). A história da hanseníase remete, portanto, "ao que é do passado e nos é ainda contemporâneo, ou ainda, apresenta um sentido para nós do contemporâneo não contemporâneo" (DOSSE, 2012, p. 11).

Questões ligadas à reparação de direitos também evidenciam a atualidade do tema. Em 2007, a Lei 11.520, determinou que toda pessoa internada compulsoriamente nos Hospitais Colônias e leprosários da rede oficial do governo para o tratamento da hanseníase até 1986, tem direito a uma indenização vitalícia a ser paga pelo Estado brasileiro. Atualmente o debate volta-se à "segunda geração": os filhos que foram separados dos pais e buscam igualmente o direito à reparação". Lugar de morar, lugar de cuidar, o Hospital e seus múltiplos significados atribuídos por aqueles que, de alguma forma, tiveram suas existências marcadas pela instituição, transformam a exposição em uma oportunidade, em um instrumento no processo de desistigmatização da doença, auxiliando a recuperar a autoestima desses sujeitos e permitindo o empoderamento de suas ações como cidadãos, motivando a reivindicação de seus direitos. A capilaridade dessas ações poderá, enfim, contribuir para a diminuição do tamanho do muro imaterial que separa os moradores do Hospital Colônia Santa Teresa do restante da sociedade.

\section{Considerações finais}

O isolamento compulsório como forma de profilaxia produziu cotidianos e sociabilidades próprios. A criação de um espaço de memória sobre história da doença em Santa Catarina a partir das narrativas, demandas e sentidos trazidos pelos sujeitos envolvidos e protagonizado por eles, se constituiu em um desafio cujos caminhos foram sendo traçados conforme a pesquisa se desenvolvia. Sob a perspectiva da história pública, procuramos apresentar a doença e seu tratamento do ponto de vista histórico, mas com o cuidado de ter como ponto principal histórias e experiências dos que tiveram suas vidas marcadas por ela, tecendo uma história com esses sujeitos.

\footnotetext{
${ }^{8}$ Projeto de Lei N. 3.303 que tramita na Câmara dos Deputados desde 2012 e visa indenizar os filhos que foram separados dos pais em função do internamento.
} 
Nossa intenção foi criar um espaço que contasse a história da hanseníase no estado, mas a partir de uma perspectiva que envolvesse os interessados, protagonizada por eles por meio de suas falas. Um dos objetivos da exposição foi oportunizar que se pense a doença e seu tratamento historicamente, possibilitando a sua desmistificação e a diminuição do preconceito em relação a ela e seus portadores.

Lugar de morar, lugar de cuidar, o hospital e seus múltiplos significados atribuídos por aqueles que de alguma forma tiveram suas existências marcadas pela instituição, transformam a realização de uma exposição em uma oportunidade, em um instrumento no processo de desistigmatização da doença, auxiliando a recuperar a autoestima desses sujeitos e permitindo o empoderamento de suas ações como cidadãos, motivando a reivindicação por seus direitos. A capilaridade dessas ações poderá enfim contribuir para a diminuição do tamanho do muro imaterial que separa os moradores do hospital do restante da sociedade, integrando minorias.

\section{Referências}

AFONSO, M. L.; ABADE, F. L. Para reinventar as rodas: rodas de conversa em direitos humanos. Belo Horizonte: RECIMAM, 2008.

BORGES, Viviane Trindade. Carandiru: os usos da memória de um massacre. In: Revista Tempo e Argumento, Florianópolis, v. 8, n. 19, p. 04 - 33. set./dez. 2016.

BORGES, Viviane e SERRES, Juliane Conceição Primon. Leprosários ao sul do brasil de locais de sofrimento a lugares de memória. In: Acervo, Rio de Janeiro, v. 28, n. 2, p. 252-263, jul./dez. 2015.

BORGES, Viviane. MENEGUELLO, Cristina. Patrimônio, memória e reparação: a preservação dos lugares destinados à hanseníase no estado de São Paulo. In: Patrimônio e Memória. São Paulo, Unesp, Vol. 14. Julho - Dezembro, 2018.

BORGES, Viviane Trindade. Como a História Pública pode contribuir para a preservação dos patrimônios difíceis? In: MAUAD, Ana. SANTHIAGO, Ricardo. BORGES, Viviane. Que história pública queremos? São Paulo: Letra e Voz, 2018a.

BORGES, Viviane Trindade. Memória pública e patrimônio prisional: questões do tempo presente. In: Tempo e Argumento, Florianópolis, v. 10, n. 23, p. 310 - 332, jan./mar. 2018b.

BORGES, Viviane. BAUER, Leticia. Outras memórias, outros patrimônios: desafios do fazer com e para os sujeitos envolvidos. In: BORGES, Viviane. BAUER, Leticia (ogs.). História Oral e Patrimônio: Reflexões e Desafios. São Paulo: Letra e Voz, 2018. 
CAPORRINO, Amanda W; UNGARETT, Ada A.P. Remanescentes de um passado indesejado: os estudos de tombamento dos exemplares da rede paulista de profilaxia e tratamento da hanseníase. In: Revista CPC, USP São Paulo, n.21.

CHOAY, Françoise. A alegoria do patrimônio. São Paulo: Estação Liberdade, 2006.

DOSSE, François. História do tempo presente e historiografia. In: Revista Tempo e Argumento, Florianópolis, v. 4, n 1, p. 5-23, jan./jun., 2012.

FRISCH, Michael. A shared authority: essays on the craft and meaning of oral and public history. Albany: State University of New York, 1990. 273p.

GROOT, Jerome. Consuming history: historians and heritage in contemporary popular culture. New York: Routledge, 2016.

MACIEL, Laurinda Rosa. A Solução de um mal que é um flageloll Notas históricas sobre a hanseníase no Brasil do século XX. In: NASCIMENTO, Dilene Raimundo do; CARVALHO, Diana Maul de. et al. Uma História Brasileira das Doenças. Brasília: Paralelo 15, 2004.

MATTOS, D. M. Fora do Arraial: "lepra" e instituições asilares em Santa Catarina (1940-1950). São Paulo. 2002. Dissertação (Mestrado em História Social) Faculdade de Filosofia, Letras e Ciências Humanas da Universidade de São Paulo, 2002.

NOIRET, Serge. In: FARNETTI, Paolo. BERTUCELLI, Lorenzo. BOTTI, Alfonso (orgs). Public History Discussioni e pratiche. Milano: Mimesis, 2017.

PEIXOTO, Paulo. Patrimônio e sociedade. Comunicação apresentada na conferência $O$ Património como Oportunidade e Desígnio: Ciência, Sociedade e Cultura, integrada no Dia Internacional dos Monumentos e Sítios: O Património e a Ciência!, 18 de Abril de 2009, Auditório da Faculdade de Direito da Universidade de Coimbra.

RICOEUR, Paul. A memória, a história e o esquecimento. Campinas: Ed. da Unicamp, 2007.

RICOEUR, Paul. Tempo e narrativa I. São Paulo: Martins Fontes, 2010.

SANTHIAGO, Ricardo. História pública como prática e campo de reflexões: debates, trajetórias e experiências no brasil. Texto apresentado como parte do relatório da bolsa PNPD 2013-2014, realizado no PPGH-UFF.

SANTHIAGO, Ricardo. História pública e autorreflexividade: da prescrição ao processo. In: Tempo e Argumento, Florianópolis, v. 10, n. 23, jan.-mar. 2018b, p. 286-309.

SEVCENKO, Liz. Prison public memory in the era of mass incarceration. In: American Quarterly, volume 68, number 3, September 2016, p.823-834. 
SILVA, Claudia Cristina dos Santos. Crianças indesejadas: estigma e exclusão dos filhos sadios de portadores de hanseníase internados no Preventório Santa Terezinha 1930-1967. Dissertação (Mestrado). Universidade de São Paulo, São Paulo, 2009.

SCHMIDT, Benito. A patrimonialização do trauma no Brasil e na Argentina após as ditaduras de segurança nacional: entre o íntimo e o público. In: FLORES, Maria Bernardete Ramos; PETERLE, Patricia (orgs.). Historia e Arte. Herença, Memória, Patrimônio. São Paulo: Rafael Copetti Editor, 2014.

ZEN, Maria Dalla Zen. Entre a Utopia e a Atopia: a experiência do Programa Lomba do Pinheiro, Memória, Informação \& Cidadania, Porto Alegre-RS. In: Cadernos do CEOM - Ano 27, n. 41 - Museologia Social, 2014.

\section{Legislação}

DECRETO N. 16.300, de 31 de dezembro de 1923 [Aprova o regulamento do Departamento Nacional de Saúde Pública] In: http://www.planalto.gov.br/ccivil_03/decreto/1910-1929/D16300.htm. Acesso em 19/06/2017.

LEI N. 9010, de 29 março de 1995 [Dispõe sobre a terminologia oficial relativa à hanseníase e dá outras providências] In http://www.camara.gov.br/legin/fed/lei/1995/lei-9010-29-marco-1995-348623-normaAcesso em: 19/06/2017.

LEI N. 11.520, de 18 de setembro de 2007 [Dispõe sobre a concessão de pensão especial às pessoas atingidas pela hanseníase que foram submetidas a isolamento $e$ internação compulsórios]. In: http://www.planalto.gov.br/ccivil_03/_ato20072010/2007/Lei/L11520.htm. Acesso em: 18/12/2015. Acesso em 03/06/2017.

PROJETO DE LEI N. 3.303, de 29 de fevereiro de 2012 [Dispõe sobre indenizar os filhos que foram separados dos pais em função do internamento]. In:http://www.camara.gov.br/proposicoesWeb/prop_mostrarintegra?codteor=966772\&fi lename $=P L+3303 / 2012$. Acesso em 03/06/2017.

\section{Fundos documentais e sites}

Site Oficial do Kalaupapa National Historical Park. In: https://www.nps.gov/kala/index.htm. Acesso em 19/07/2017.

Site IDEA - International Association for Integration, Dignity and Economic Advancement - Leprosy and Human Rights, Past and Present. In: http://www.idealeprosydignity.org/. Acesso em 19/07/2017.

ILA - International Leprosy Association. In: http://www.leprosy-ila.org/do.php/Home. Acesso em 19/07/2017.

Nippon Foundation - Elimination of Leprosy. In: http://www.nipponfoundation.or.jp/en/what/projects/leprosy/. Acesso em 19/07/2017. 
Documentários

Santa Teresa. Direção: Eduardo Baggio, Brasil, 2014, 64 min. 